in de-mystifying biodiversity and educating Canadians. One of the projects of the Institute that focusses on education and awareness is the yearly great Canadian Bio-Blitz, which involves individuals and communities in monitoring local biodiversity.

Ken Armson, with the Ontario Professional Foresters Association, indicated that there will be more accountability as a result of recent legislation licensing people who practice forestry in Ontario. He outlined the various aspects of the Scope of Practice set out in the legislation.

A healthy and spirited question period followed the panel presentations. In closing, EOMF President Ray Fortune urged all attending to plant at least one tree in 2001 and to become a member of a forest/environment related organization of choice.

You can look forward to an equally interesting Christmas Forest Seminar in 2001. We hope to see you there!

\section{Planned Section Meetings}

- February 19, 2001, Forestry History in the Ottawa Valley.

خ- April, 2001, Forest Industry Outlook. June, 2001, Annual General Meeting \& Forest Management in the Gatineau Field Trip.

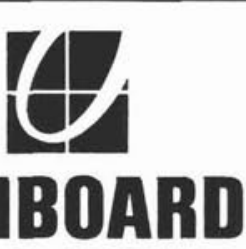

UNIBOARD CANADA INC $\circledast$

A CIF/IFC Corporate Sustaining Member

Are You Moving?

Please help us to keep our records up to date. Let us know when your address changes. There are four ways to tell us:

1. Email us at cif@cif-ifc.org

2. Fax us at (613) 234-6.181

3. Telephone us at (613) 234-2242

4. Mail us at 151 Slater Street, Suite 606, Ottawa, ON KIP $5 \mathrm{H} 3$.

\title{
Forestry Education News
}

In September of 2000, the fourth group graduated from the Alberta Advanced Forest Management Institute (AAFMI) program (see photo below). Most individuals take approximately $41 / 2$ years to complete the six, 2-week modules. Return dates for each module are scheduled for no less than six months and no greater than 12 months.

Class sizes vary from mid teens to high twenties in number. A class size of 22-24 candidates appears to optimize synergy, class challenges to the science of forestry and interchange of ideas. Technical (information) transfer is done through lectures, class projects, workshop and computer lab sessions and field trips. Competence and understanding of material delivered is measured through evaluation processes such as written examinations, class participation, oral presentations, written exercises, computer modeling lab assignments, and compilation and analysis of field data. Most modules also have a pre-course assignment, which may be used in the evaluation process. Each candidate is required to achieve an overall mark of $65 \%$ to be granted a pass in that module.
Total enrollment to date is 154 of which 52 individuals have already graduated. Faculty for each module consists of a facilitator and a number of speakers composed of scientists, researchers, academics and leading experts from across North America. In a given year, the program will engage approximately 80 90 faculty (speakers) to deliver technical transfer sessions in the various modules.

The program experiences a high level of learning opportunity due to extraordinary enthusiasm, energy, and the positive attitude of individuals attending the program. This synergy is enhanced by a distinctive class composition. Enrollment between forest industry/government candidates continues to stay around a $50 \% / 50 \%$ split and the graduate forester/forest technologist split remains at a $70 \% / 30 \%$ split. Added to this unique mix are candidates from the Yukon, Northwest Territories and Saskatchewan, who make up approximately $10 \%$ of total enrollment.

AAFMI acknowledges the strong support from the Silviculture Insitute of British Columbia (now called the Forest Management Institute of BC) after which

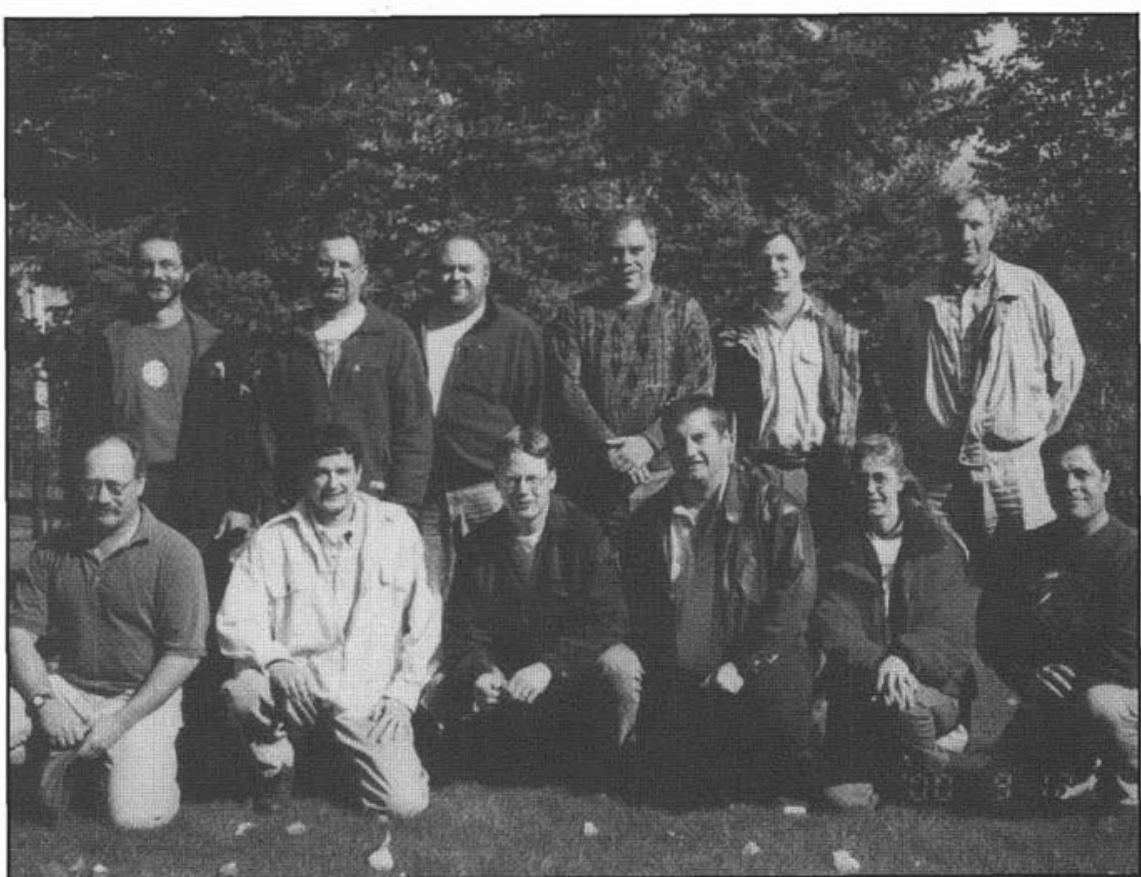

Module VI (Group 4) Graduating Class: Back row (L-R): Larry Matwie, Jean-Claude Lussier, Allan Benson, Rick Smee, Scott Milligan, Steve Luchkow. Front row (L-R): Ken Yackimec, Rob Mueller, Fulton Smyl, David Kent, Florance Neimi, Rick Moore. 


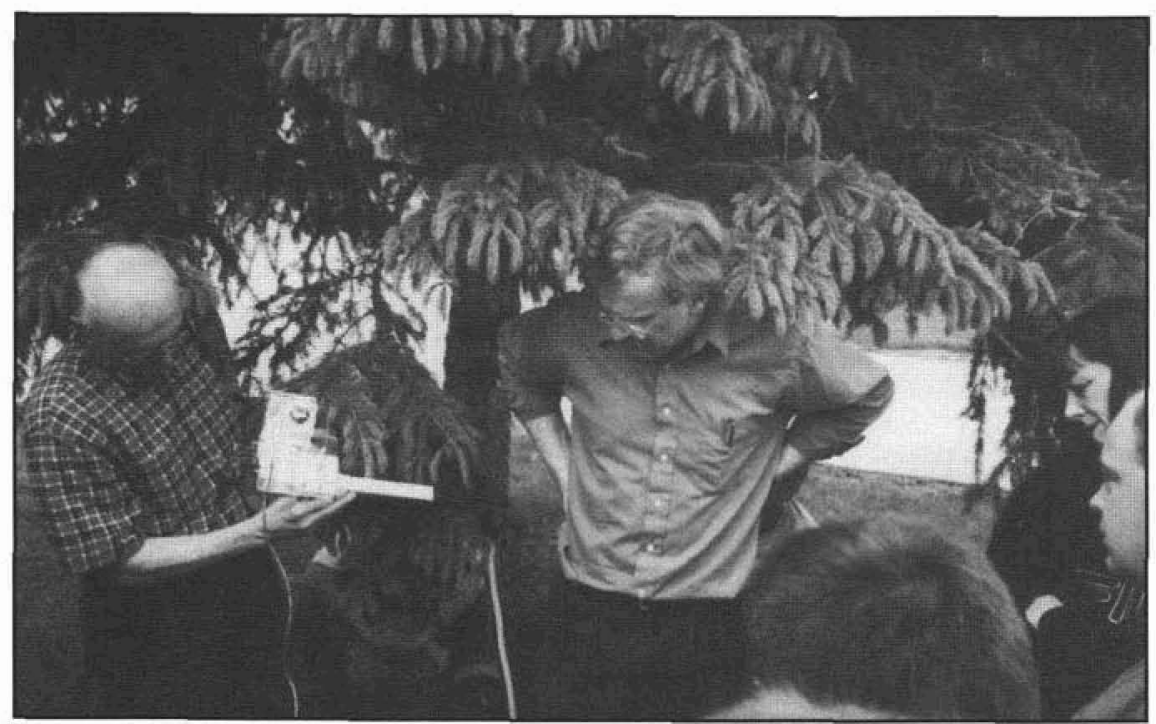

Module I: Dr. Vic Lieffers (University of Alberta), with assistance from Module I facilitator Dr. Rich Rothwell, is demonstrating to the class how to measure photosynthetic uptake processes of a tree.

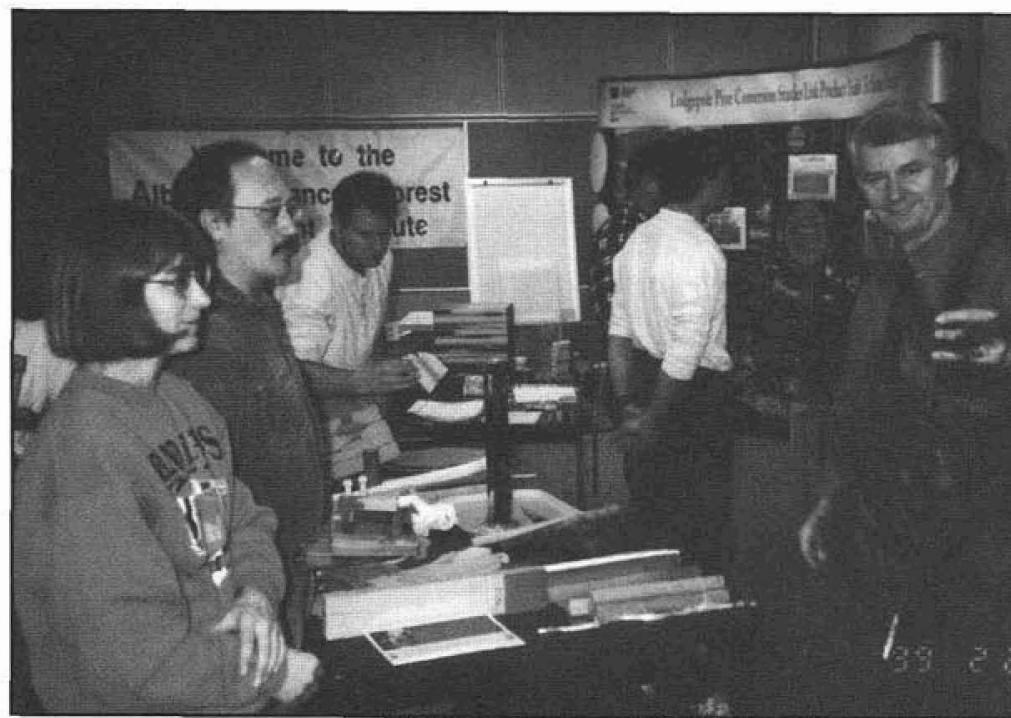

Right: Module V: Doug Walker (Timberline Forest Inventory Consultants) is explaining the effects that insufficient stocking and juvenile spacing can have on future timber supply. this program was initially modeled. Since that original establishment stage, AAFMI has undergone numerous revisions. The program currently reflects boreal forest conditions, Alberta social, political and economic realities and addresses both silviculture and aspects of forest management planning.

Strategic planning for the program is conducted by an AAFMI Board of Directors. The Board consists of four members from the forest industry, four members from the Alberta Land \& Forest Service and one member from a forestry consulting firm.

Recent inquiries from Ontario and Quebec indicate that there is interest in both of these jurisdictions for establishing similar continuing forestry education programs. It is heartening to see that this very important facet of managing forests in Canada is being recognized as an integral and necessary part of doing business. It is also encouraging to know that the folks who look after our forests have an opportunity, through continuing education, to keep their management skills at state-of-the-art.

For more information, contact the writer or visit our web site: (www.gov. ab.ca/env/resedu/etc/fm.html)

Leff: Module IV: Les Jozsa (FERIC) is demonstrating to the class the effects that various silvicultural treatments can have on tree growth and subsequent wood quality.

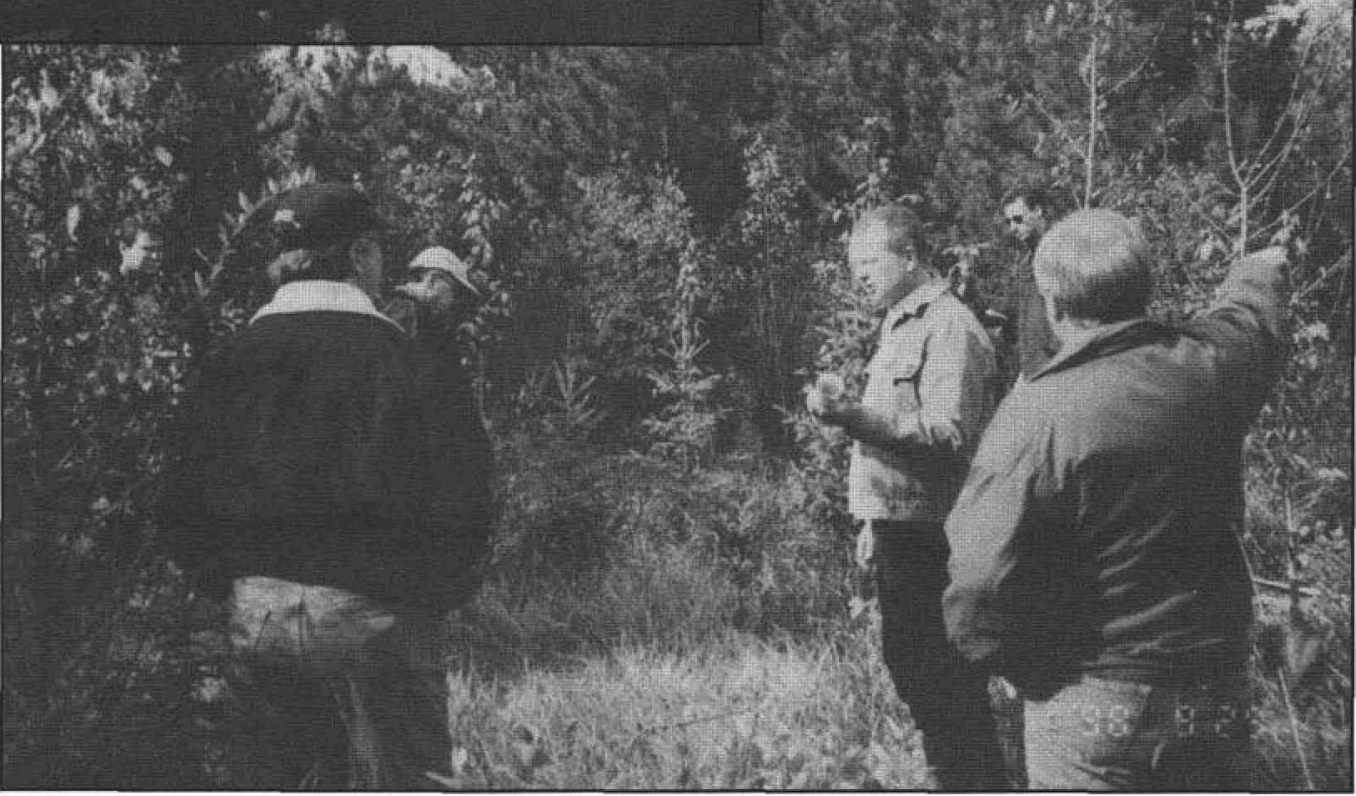

